\title{
Analysis of the number of switches of on-load tap changer of a power transformer for field substation, taking into account discrete time and voltage level sampling
}

\author{
T.V. Tabachnikova ${ }^{1, *}$, L.V. Shvetskova ${ }^{1}$, and A.V. Yumalin ${ }^{1}$ \\ ${ }^{1}$ Almetyevsk State Oil Institute, 2 Lenina St., Almetyevsk, 423450, Tatarstan, Russia
}

\begin{abstract}
The introduction of "smart grids" technologies poses the problems of multi-criteria determination of the optimum voltage in the main substation of the object under study. In this study the busbar sections of the field substation of the oil and gas company is considered as the main substation. This paper studies regulation of voltage level in an electrical network using on-load tap changer (OLTC) of a power transformer for field substation of an oil and gas enterprise. Considered are approaches for voltage regulation taking into account the development of smart grid technologies. The authors have developed a universal method for determining the optimal voltage level on the busbar sections of a field substation, which allows for selection of the optimum voltage in accordance with certain parameters: loss of active, reactive power, voltage, electricity consumption, specific consumption or efficiency factor of artificial oil lift. The actual daily graphs of consumption of active, reactive power and voltage level at one of the field substations of PJSC Tatneft were studied. The operation mode of on-load tap-changer drive of the field transformer was modeled, taking into account the calculated optimal values of voltage and the dead zone. The paper presents the results of study of automatic voltage regulation on busbar sections of a field substation, taking into account the constraints for tap changer switches of a power transformer.
\end{abstract}

\section{Introduction}

The expansion of area of fields being developed is characterized by an increase in electricity consumption. It causes a need for the development of power supply system, so the issues of economical use of electricity are becoming especially relevant. At any production, the owner seeks to save specific electricity consumption per unit of production in order to reduce its cost [1-3].

Smart Grid technologies are actively developing around the world. Smart Grid predetermines the global automation and informatization of electric power systems in order to fulfill reliable grid modes. Smart Grid technologies are being actively implemented at oil and gas production enterprises, therefore, optimization of voltage modes, taking into account the adoption of new control algorithms, remain relevant today [4,5].

Many scientific works devoted to finding approaches for optimal voltage regulation in power supply systems, adopt the criterion for saving electricity as the loss of active power, reactive power and voltage in electrical network [6-11]. However, the authors of the present article are inclined to believe that not all enterprises need to use this particular criterion. As a criterion for optimization voltage level at busbar sections of field substations it is proposed to use a coefficient showing the efficiency of artificial oil lifting, measured in $\mathrm{m} 3 /$ day $\bullet \mathrm{kW}$. This coefficient was elaborated while analyzing modeling of operation modes of field distribution network [9]. The authors assessed the optimum voltage for the minimum specific consumption of electricity for mechanized oil production and for the maximum volume of produced oil emulsion.

Transformers equipped with on-load tap-changers (OLTC) are installed at the field substations of the Russian and international oil and gas producing companies. They are used to regulate the voltage level and maintain the voltage at the typical points of power supply system within the permissible limits in accordance with the Russian State Standard GOST 32144-2013. It should be noted that when determining the optimal voltage level and during its automated stabilization using the power transformer of the field substation, it is important to analyze the operating mode of the on-load tap-changer [12]. Exceeding the number of OLTC switches per day results not only in failure of the tap-changer itself, but also in the subsequent repair of transformer. The constraints specified in passport for transformers installed at field substations assign that the number of OLTC switch per day should not exceed 25.

The present study is devoted to the regulation of voltage level in electrical network using the on-load tapchanger of power transformer of the field substation of an oil and gas company. The aim of this work is to analyze the number of switches of OLTC of a field substation power transformer taking into account time

Corresponding author: tvtab@mail.ru 
sampling and automatic stabilization of the optimal voltage level.

\section{Materials and methods}

The authors used a technique for determining the optimal voltage level in the main substation, i.e. on busbar sections of a field substation, taking into account the operation parameters of the field equipment as a function of voltage. Analysis of the simulation results using showed that there is no single optimum voltage. One criterion must be chosen for the selection of optimal voltage by the energy services. When the efficiency of artificial oil lifting, $(\mathrm{m} 3 /$ day $\bullet \mathrm{kW})$ is used as this criterion, the voltage optimum shifts to the range of values from 0.9 Unom to $0.98 \mathrm{Unom}$. Taking into account the technical constraints on the OLTC operation, it is important to study the possibility of stabilizing the optimal voltage in the main substation in the proposed range of values. It is explained by the fact that most often, power services do not set the OLTC to automatic operation and try to set higher voltages at the substation in the range from 1.05Unom to $1.1 \mathrm{Unom}$. On-load tapchangers must be operated according to the manufacturer's instructions. They must be constantly in operation, and the number of operations must be recorded by a special counter. The choice of dead zone should be carried out starting from a change in voltage level on high voltage side during the day and taking into account the constraints on the number of switches per day [13].

To determine the number of tap-changer drive switches, daily voltage schedule was recorded using the commercial metering unit of the field substation. The graphs were obtained from a field substation, which did not automatically stabilize the voltage level on the $6 \mathrm{kV}$ bus sections. The transformer operated on a tap, which provided a voltage addition of $+10 \%$. Taking into account the addition introduced by the secondary winding of this transformer, the voltage on the $6 \mathrm{kV}$ busbar sections increased to 1.16 of Unom. The voltage graph, recorded on the high voltage side, is converted into low voltage through the transformation ratio. The stabilized voltage graph (UOLTC) is simulated in order to determine the number of tap changer switching operations. An algorithm for automatic voltage stabilization to determine the number of tap changer switches taking into account the real voltage graph on the high voltage side of the field substation is implemented in Mathcad. When modeling the operating mode of a field distribution electric network, the optimal voltage level was calculated. This value became the initial data for the algorithm (Ustab). This value may not correspond to voltage provided by one of the control taps of the transformer. Next, the tap of the transformer is selected, which can actually provide the voltage value closest to the optimal one, and the dead zone (su, sl). The following should be taken into account: the current voltage level in the supply network of the field substation, the regulation range that the transformer can provide, the regulation step, the additives introduced by the primary and secondary windings of the transformer. When the values go beyond the upper or lower limit of the dead zone, the switching cycle of taps is carried out until voltage is in the dead zone. The number of switches is counted and the deadband is adjusted.

\section{Results and discussion}

Figures 1-4 show daily graphs of voltage changes on busbar section of the field substation for winter, spring, summer and autumn. The graphs show the actual and stabilized voltage levels at the main substation.

The transformer installed at the substation has a regulation range of $\pm 9 \times 1.78 \%$, i.e. $\pm 16 \%$ of the rated voltage. The simulation of OLTC drive operation was carried out with the following settings: the stabilized voltage of $5980 \mathrm{~V}$, which corresponds to the control tap 3 , the dead zone was taken equal to $\pm 3 \%$, the holding time was $360 \mathrm{~s}$.

Actual ranges of voltage variation on the high voltage side are the following: $(1.102 \div 1.145)$ Unom in winter, $(1.102 \div 1.145)$ Unom in autumn, $(1.102 \div 1.145)$ Unom in spring, $(1.102 \div 1.145)$ Unom in summer. When simulating the voltage mode with stabilization of the optimal voltage level in main substation, the following number of tap changers was obtained: 11 in winter, 15 in autumn, 15 in spring and 9 in summer. The obtained values do not exceed the constraints indicated in passports of power transformers (20-25).

The following notations are used in Figures: $U_{\text {OLTC }}$ is the voltage graph during automatic stabilization using the on-load tap-changer of power transformer; $U_{\mathrm{vlf}}$ is the voltage graph on the low voltage side of the field substation without automatic voltage stabilization; $U_{\text {stab }}$ is the voltage being stabilized; $s_{\mathrm{u}}, s_{1}$ are the upper and lower limits of the dead zone, respectively.

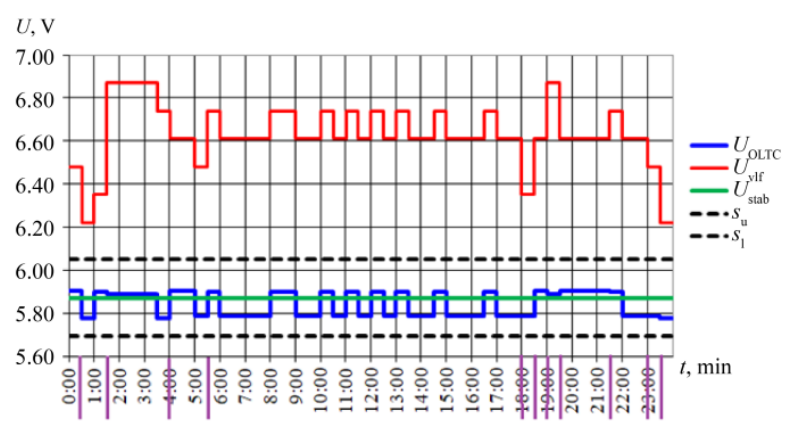

Fig. 1. Daily graph of voltage on busbar section of the field substation in winter. 


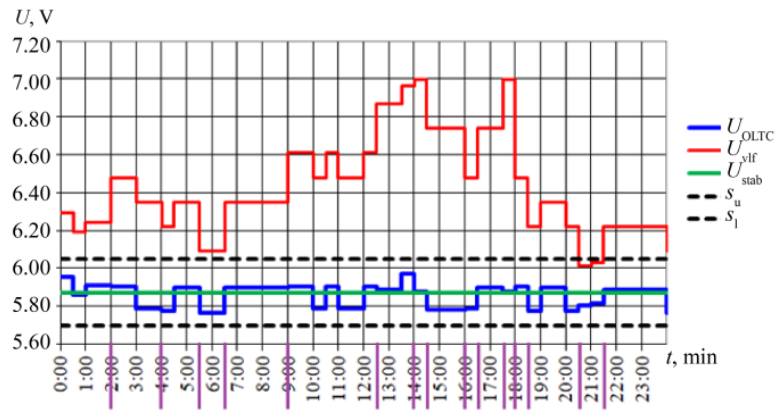

Fig. 2. Daily graph of voltage on busbar section of the field substation in autumn.

Analysis of results of modeling the operation modes of field distribution electric network shows that the optimal voltage level on busbar sections of the field substation can be determined according to the selected optimization criterion: either minimum losses, or minimum specific power consumption, or by the oil production efficiency factor. In the absence of voltage stabilization at a higher hierarchical level relative to the field substation, i.e. at a nodal substation, the number of switches of the on-load tap-changer drive of power transformer with a dead zone less than $+3 \%$ may exceed the permissible number of switches per day. Frequent switches of tap changers lead to a decrease of its technical resource and can lead to premature failure, which will entail a transformer repair.

In order to maintain optimal operation parameters in the distribution field electric network, using calculation of the optimal voltage level according to the proposed algorithm, it is proposed to perform regulation using the on-load tap-changer. It means a command is given to change the setting of the stabilized voltage level using a microprocessor-based device for automatic control of on-load tap-changer electric drive of the power transformer under load.

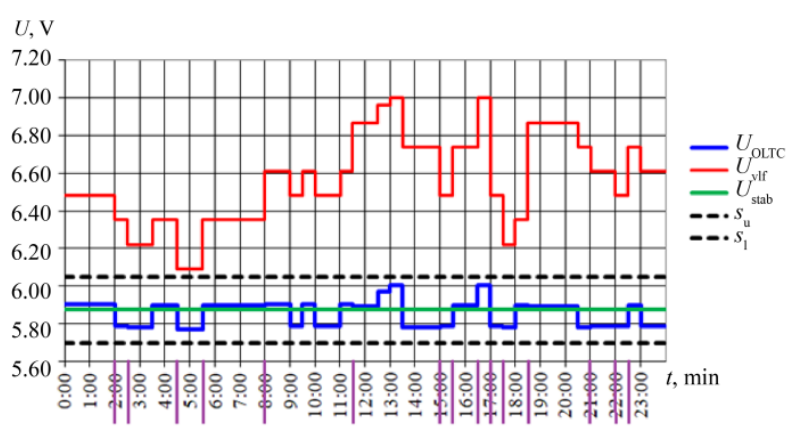

Fig. 3. Daily graph of voltage on busbar section of the field substation in spring.

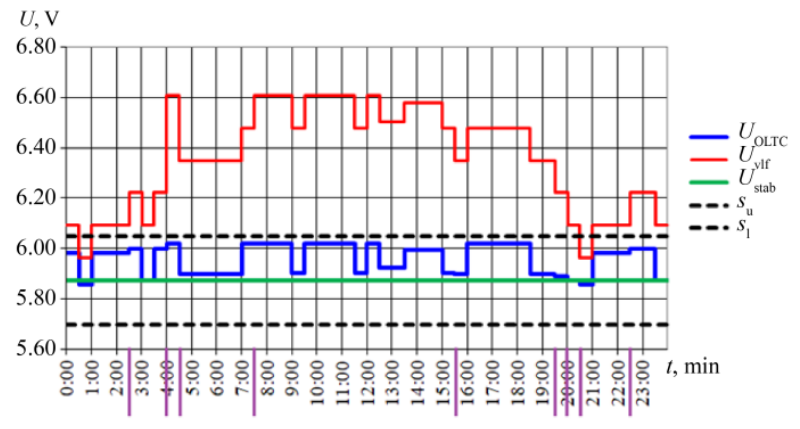

Fig. 4. Daily graph of voltage on busbar section of the field substation in summer.

Taking into account the introduction of smart grid technologies, the authors propose to switch the voltage regulator drive as an internal disturbing factor arises. This means it should switch on fact of events occurring in the distribution field electric network, when electrical complex of the production well or electrical complex of auxiliary equipment are turned on or off $[14,15]$. In order to ensure that the number of OLTC switches does not exceed the permissible values, it is important to analyze the periods of change in load according to the actual graphs of voltage and current obtained from the commercial meter of the field substation (Figure 5).

The following designations are used in Figure 5:

$U_{\text {av }}$ and $I_{\text {av }}$ are the average daily voltage and current;

$U_{\max }, U_{\min }$ and $I_{\max }, I_{\min }$ are the maximum and minimum deviations of voltage and current;

$U_{\text {eq }}$ and $I_{\text {eq }}$ are the equivalent values of voltage and current;

$\Delta \sigma_{u \text { max }}, \Delta \sigma_{u \text { min }}$ and $\Delta \sigma_{i, \text { max }}, \Delta \sigma_{i, \text { min }}$ are the root-meansquare deviations of voltage and current;

$U_{e q}+\Delta \sigma_{u \text { max }} ; \quad U_{e q}+\Delta \sigma_{u \text { m.min }} ; I_{e q}+\Delta \sigma_{i, \text { max }} ; I_{e q}+\Delta \sigma_{i \text { min }}$ are the maximum and minimum deviations of equivalent voltage and current.

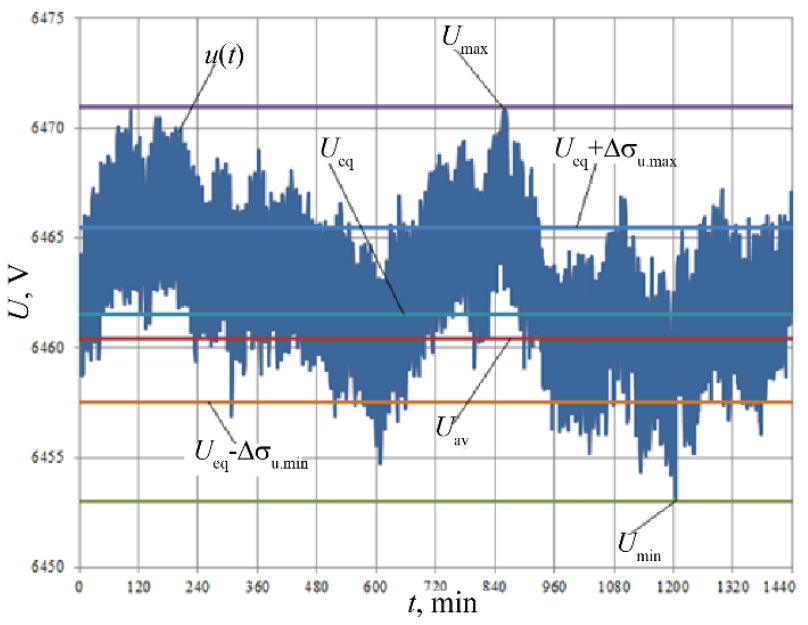

Fig. 5. Daily voltage graph of the main substation.

In order to have the amount of switches not more than 25 times a day, the minimum interval between switches $T_{\min }=\frac{24}{25}=0.96$ hours, i.e. 58 minutes. If less than 58 minutes have passed after the last switch of 
OLTC, the command to switch is transferred to the time corresponding to the expiration of the minimum switch interval.

According to the graph shown in Figure 5, load changes occur at intervals of 10, 4 and 6 hours. Four facts of load changes occurred during a day. Therefore, taking into account the OLTC drive switch to maintain voltage within the specified deadband limits (Figures 14), the total maximum number of switches is 19 , i.e. does not exceed the limitation of 25 switches $[15,16]$.

A preliminary economic calculation of the proposed measures to stabilize the optimal voltage level on the busbar sections of field substations showed that the expected annual economic effect can be from 500 ths. rubles to $2 \mathrm{mln}$. rubles for one input of the substation depending on the number of outgoing lines.

\section{Conclusions}

The authors considered voltage regulation of power transformer with the introduction of smart grid technologies, which take into account actual changes in the network load. The number of switches of power transformer tap changer was analyzed. It was determined that when using this device, the number of voltage regulator switches of power transformer under load will not exceed the permissible values specified in the passport of manufacturers (20-25), while the dead zone should not be less than $\pm 3 \%$.

\section{References}

1. F. Nepsha, R. Belyaevsky, V. Efremenko, K. Varnavskiy, Modern problems of increasing coal mines power supply efficiency, E3S Web Conf., 105 (2019)

2. V.I. Sitas, Fedyukhin, I.G. Akhmetova, A. Mitrofanov, S.O. Makoev, A. Asadpoori, A.A. Sinitsyn, E.A. Kikot, Assessment of technical and economic efficiency indicators of cogeneration in modern market conditions, Int. J. Civ. Eng. Technol., 10, 2106-2117 (2019)

3. I. Akhmetova, A. Tyfetylov, A. Tamakchi, G. Khadiyllina, O. Derevianko, Z. Syed, Improving the competitiveness of automobile engineering enterprises by advancement the internal control over its indicators, Int. J. Civ. Eng. Technol., 9, 18651876 (2018)

4. Y. Sychev, R. Zimin, M. Aladin, The assessment of the series active filter efficiency in power supply systems of oil production enterprises, E3S Web Conf., 140 (2019)

5. L.V. Larchenko, R.A. Kolesnikov, L. Mukhametova, Russian oil and gas industry as a sphere of international interests and economic cooperation, E3S Web Conf., 161 (2020)

6. R.B. Jalilov, S.T. Latipov, G.N. Aslanova, A.A. Akhmedov, S.P. Shayimova, Key directions of development of measures to improve the reliability of electrical power systems, E3S Web Conf. 139 (2019)

7. S.T. Ismoilov, Voltage regulation at substations of a distribution electric network with control of the mode of the adjacent area. Thesis of dissertation for the degree of candidate of technical sciences (Novosibirsk, 2014)

8. N.A. Kardzhaubaev, Multi-agent voltage regulation in multi-connected electrical networks. Thesis of dissertation for the degree of candidate of technical sciences (Novosibirsk, 2018)

9. D.N. Nurbosynov, T.V. Tabachnikova, Multilevel hierarchical optimization of the voltage regime of the power supply system of an oil and gas production enterprise, Bull. Samara State Tech. Univ. Ser. Eng. Sci., 1 85-95 (2017)

10. S. Khushiev, O. Ishnazarov, O. Tursunov, U. Khaliknazarov, B. Safarov, Development of intelligent energy systems: The concept of smart grids in Uzbekistan, E3S Web Conf., 166 (2020)

11. H. Nazaripouya, H.R. Pota, C.C. Chu, R. Gadh, Real-Time Model-Free Coordination of Active and Reactive Powers of Distributed Energy Resources to Improve Voltage Regulation in Distribution Systems, IEEE Trans. Sustain. Energy, 11, 14831494 (2020)

12. L. Jin, Y. Cai, A Review of Fault Diagnosis Research on On-Load Tap-Changers, E3S Web Conf., 155 (2020)

13. T.V. Tabachnikova, D.N. Nurbosynov, E.V. Ryumin, Analysis of the influence of voltage deviation on the loss of electrical energy and the number of switches of the OLTC drive of power transformers Materials of the international scientific and practical conference dedicated to the 60th anniversary of oil and gas education in the Republic of Tatarstan, Achievements, problems and prospects for the development of the oil and gas industry, 194-195 (2016)

14. T.V. Tabachnikova, A.V. Sharygin, A.V. Makht, Development of structure of an adaptive system for control of energy parameters in the distribution electrical network, Collect. Sci. Pap. Angarsk State Tech. Univ. 227-232 (2016)

15. D.N. Nurbosynov, T.V. Tabachnikova, A.V. Sharygin, Implementation of a regulator for control of on-load tap-changer electric drive at the software level, using the example of a mathematical model, Improv. Reliab. energy Effic. Electr. Syst. complexes. Interuniv. Collect. Sci. Pap., 263-267 (2016)

16. D.N. Nurbosynov, T.V. Tabachnikova, A.V. Yumalin, E.D. Nurbosynov, Multilevel voltage stabilization and optimization of electrical energy losses in an electrical distribution network, Sci. notes Almetyevsk State Oil Inst., 17 218-226 (2017). 